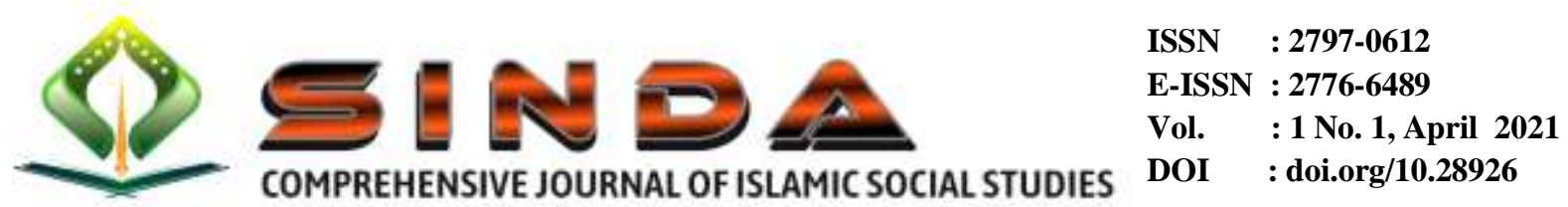

\title{
Efektivitas Focus Group Discussion (FGD) dan Psikodrama untuk Mengurangi Stres Akademik pada Mahasiswa Baru
}

\author{
Defi Astriani ${ }^{(1)}$, Karisma Dewi Puspasari ${ }^{(2)}$ \\ ${ }^{1}$ Universitas Nahdlatul Ulama Blitar, Indonesia \\ ${ }^{2}$ Institut Agama Islam Tribakti, Indonesia \\ Email: ${ }^{1}$ defi45astriani@gmail.com, ${ }^{2}$ krsmdw@gmail.com.
}

\begin{abstract}
Informasi artikel ABSTRACT
Sejarah artikel: $\quad$ A phenomenon often experienced by new students who are not familiar with the academic Diterima:

20 April 2021

Revisi: environment is academic stress. Students with academic stress feel unable to face existing

25 April 2021

Dipublikasikan

30 April 2021

Keyword:

Focus Group

Discussion (FGD)

Psychodrama
\end{abstract}

Academic stress

New students

\begin{tabular}{ll}
\hline & ABSTRAK \\
\hline Kata Kunci: & Fenomena yang sering dialami oleh mahasiswa baru yang belum terbiasa dengan \\
Focus Group & lingkungan akademik adalah stress akademik. Mahasiswa dengan stress akademik merasa \\
Discussion (FGD) & tidak mampu menghadapi tanggungjawab, tugas dan organisasi yang ada. Sehingga akan \\
Psikodrama & berdampak pada koonsentrasi dan prestasi akademik. Agar permasalahan terkait stress \\
Stres Akademik & akademik ini tidak berkepanjangan maka diperlukan sebuah penanganan. Penelitian ini \\
Mahasiswa Baru & bertujuan untuk mengurangi stres akademik pada mahasiswa baru. Quasi experiment \\
& adalah jenis penelitian yang digunakan dengan metode non-randomized one group pretest \\
& postest design. Subjek penelitian berjumlah 5 orang. Hasil penelitian dianalisis \\
& menggunakan SPSS for windows ver. 21, yaitu menggunakan analisis parametrik Paired \\
& Sample T-Test. Analsis hasil penelitian menunjukkan nilai p < 0.05 (p = 0.01) artinya \\
& skor tersebut signifikan. Hal ini menunjukan bahwa antara skor sebelum dan skor sesudah \\
& intervensi menunjukan adanya penurunan stres akademik secara signifikan.
\end{tabular}

\section{Pendahuluan}

Masa kuliah tentu berbeda dengan masa sekolah. Bagi sebagian orang beranggapan bahwa kuliah lebih menyenangkan dibandingkan dengan masa sekolah. Mereka berpikir jika perkuliahan lebih santai, jam kuliah lebih fleksibel dan tugas tidak sebanyak waktu sekolah. Namun anggapan ini tentu akan berkebalikan dengan realitanya. Karena saat kuliah akan berhadapan dengan sebuah tanggungjawab baru sebagai mahasiswa. Selain tuntutan tugas, mahasiswa baru juga akan berhadapan dengan lingkungan baru dan tentunya dibutuhkan kemampuan sosialisasi yang baik. Dimana beban tugas akan berbeda dengan masa sekolah. Banyak mahasiswa terutama mahasiswa baru yang merasakan stress akademik akibat tuntutan tanggungjawab ini (Angola \& Ongori, 2009). Merasa tidak kuat dan akhirnya menjadi stressor dan berpengaruh pada mood, konsentrasi serta prestasi akademik.

Fenomena-fenomena inilah yang sering ditemui di lapangan terutama bagi mahasiswa 
baru yang belum terbiasa berada di lingkungan perkuliahan. Mahasiswa yang mengalami stress akademik tentu akan memunculkan dampak negative bagi proses belajarnya selama kuliah (Jongaratnam, 2004). Mereka akan menghindari tugas sehingga tugas semakin menumpuk, mengerjakan tugas namun semaunya dengan penuh tekanan, serta ada yang tidak mengerjakan tugas sehingga menjadi semakin tertekan dengan tugas yang semakin menumpuk dan pada akhirnya menjadi depresi (Klonske \& Hoe, 2003).

Stress ialah respon individu ketika berhadapan dengan stressor dan tidak mempunyai kemampuan untuk mengatasinya (Santrock, 2012). Individu biasanya tidak mempunyai kemampuan coping yang baik ketika berhadapan dengan permasalahan dalam hidupnya dan cenderung membiarkannya hingga muncullah stress (Sutarjdo, 2005). Sumber stres pada mahasiswa salah satunya adalah tugas. Tugas tidak akan pernah bisa dihindari oleh setiap mahasiswa. Tugas bervariasi disetiap mata kuliah, baik itu tugas individu maupun tugas kelompok (Misra \& McKean, 2000).

Berdasarkan hasil asesmen yang telah dilakukan pada mahasiswa baru di Universitas Muhammadiyah Malang, didapatkan bahwa beberapa dari mereka ada yang mengalami stress akademik dan ada juga yang tidak mengalami stress akademik. Mahasiswa yang mengalami stres akademik menganggap bahwa beban kuliah dan kegiatan organisasi saat ini terlalu berat, sehingga menimbulkan tekanan tersendiri bagi mereka. Sedangkan mahasiswa yang tidak mengalami stres, mereka lebih cuek dengan keadaan mereka saat ini, dalam artian mereka tidak terlalu memikirkan beban yang harus dihadapi dan tetap menjalani kehidupan mereka sesuai dengan jalan kehidupan masingmasing. Hal ini menunjukkan jika mahasiswa yang tidak mengalami stress akademik mempunyai kemampuan coping yang baik.

Beberapa penelitian menunjukkan bahwa terdapat beberapa factor yang mempengaruhi stress akademik yaitu tugas (Kumar, 2005), manajemen waktu, interaksi antara dosen dan mahasiswa, tujuan pribadi, aktivitas social, lingkungan kampus, dan kurangnya dukungan social baik dari teman atau keluarga sehingga membuat mahasiswa rentan mengalami stress akademik (Wilks, 2008). Selain itu, ekspektasi yang terlalu tinggi dari individu, orang tua maupun lingkungan juga menjadi factor mengalami stress akademik (Ang \& Huan, 2006).

Jika dibiarkan mahasiswa yang mengalami stress akademik akan merasakan jenuh, bosan, malas, tidak percaya diri, mengalami penurunan kualitas pada pembelajarannya dan akan berdampak panjang jika tidak segera diatasi dan dihilangkan. Pada intervensi kelompok ini, fasilitator ingin melakukan intervensi sekelompok mahasiswa yang mengalami stres akademik pada mahasiswa baru dengan menggunakan metode Focus Group Discussion (FGD) dan Psikodrama. FGD adalah suatu proses pengumpulan informasi dan pemecahan masalah pada suatu permasalahan tertentu yang spesifik melalui diskusi kelompok (Boateng, 2012).

Sedangkan Psikodrama ialah permaiann peran tanpa menggunakan naskah atau tanpa latihan sebelumnya (Lubis, 2016). Psikodrama digunakan untuk memberikan pemahaman kepada masing-masing subjek dari persepsi orang yang berbeda yang akan diperankan masing-masing oleh subjek dengan mendramakan permasalahan subyek. Menggunakan psikodrama karena kegiatan ini dapat dilakukan oleh semua individu pada setiap usia dan berbeda dengan brainstorming yang hanya dapat digunakan untuk usia tertentu (Orkibi, 2018).

Banyak manfaat yang bisa dirasakan dan diperoleh apabila masalah ini diteliti lebih lanjut secara mendalam, serta dapat memberikan solusi bagi mahasiswa sendiri maupun dari ruang lingkup akademik. Stres akademik sendiri sangat sering terjadi dan banyak sekali ditemukan pada mahasiswa terutama pada mahasiswa baru. Dengan memperdalam masalah, solusi terbaik, serta 
cara penanganan untuk stres akademik sendiri diharapkan jumlah mahasiswa yang merasakan stres akademik bisa berkurang dan tidak terjadi dalam jangka waktu yang lama.

\section{Metode}

Penelitian ini merupakan penelitian quasiexperiment dengan menggunakan nonrandomized one group pretest postets design. Desain penelitian dipilih berdasarkan pertimbangan peniliti bahwa tidak memungkinkan dilakukan randomisasi subjek untuk dibagi dalam dua kelompok, eksperimen dan control (Seniati et al., 2011). Penelitian ini hanya terdapat satu kelompok eksperimen tanpa adanya kelompok pembanding. Pengukuran efektifitas intervensi menggunakan skala stress akademik dengan membandingkan data pre-test dan post-test antara sebelum dan sesudah pemberian intervensi.

Subyek penelitian yang digunakan adalah mahasiswa baru berjumlah 5 orang. Dalam melakukan asesmen, metode yang digunakan yaitu: wawancara semi formal dan wawancara tertutup. Wawancara semi formal dilakukan agar dalam menggali permasalahan dapat dilakukan dengan lebih santai, bebas, dan tidak formal. Sedangkan wawancara tertutup, menggunakan pertanyaan-pertanyaan dengan jawaban "iya" dan "tidak" yang tujuannya untuk melakukan screening. Serta menggunakan kuesioner stress akademik untuk mengetahui sejauh mana stress akademik yang dialami subjek.

Intervensi kelompok ini menggunakan teknik Intervensi Focus Group Disscussion (FGD) dan juga menggunakan psikodrama. Sasaran/target intervensi adalah untuk mengurangi stress akademik mahasiswa baru. Intervensi ini terdiri dari lima sesi dan berlangsung selama 60 menit di setiap sesinya. Berikut adalah rancangan tiap sesinya:

\section{Sesi I : Building rappot}

Di tahap 1 ini, peneliti membuka kegiatan dan memperkenalkan diri dilanjutkan dengan para subjek. Kemudian menjelaskan kegiatan yang dilakukan dan memberikan informed consent agar ada kesepakatan antara subjek dan peneliti untuk mengikuti keseluruhan sesi. Para subjek memahami tujuan dan prosedur kegiatan yang disampaikan oleh peneliti dan bersedia mengikuti keseluruhan kegiatan.

Sesi II : FGD sesi 1 (membahas topic awal)

Sesi ini membahas topic awal sebelum dilakukannya proses intervensi guna mengetahui kondisi permasalahan para subjek dan factor yang menyebabkan permasalahan tersebut. Selain itu untuk menyamakan persepsi antar subjek agar seluruh kegiatan berjalan dengan lancar. Masing-masing subjek menyampaikan permasalahan akademiknya kemudian mereka dapat memahami penyebab masalah mereka masing-masing.

Sesi III : Diskusi kasus

Peneliti memberikan kasus terkait stres akademik untuk didiskusikan oleh para subyek. Setelah mendiskusikan kasus tersebut. Kemudian juga diberikan edukasi tentang bagaimana teknik-teknik dalam mengelola stres. Di sesi ini para subyek telah memahami apa saja teknik yang dapat digunakan untuk mengelola stresnya sehingga mereka tidak lagi menghindar ketika ada stressor dalam dirinya.

Sesi IV : Psikodrama

Tujuan dari sesi ini adalah untuk menemukan solusi permasalahan dari berbagai sudut pandang. Materi yang diberikan menyesuaikan dengan permasalahan subyek yang dianggap mewakili permasalahan subyek lainnya. Dalam hal ini, peneliti bertindak langsung sebagai director selama proses psikodrama.

Sebelum psikodrama dimulai, director mengambil salah satu kasus dari permasalahan subjek. Kemudian subjek memaikan drama sesuai dengan arahan director. Dari sesi ini subjek dapat mengambil kesimpulan atas solusi yang harus diterapkan dalam kehidupan ketika berhadapan dengan suatu permasalahan terutama yang berkaitan dengan akademik.

Sesi VI: Evaluasi 
Sesi terakhir adalah evaluasi untuk melihat efektivitas pemberian intervensi kepada para subjek. Evaluasi dilakukan dengan pengisian skala stress akademik sebagai data post test yang kemudian hasilnya dibandingkan dengan data sebelum intervensi (pre-test).

Teknik Analisis Data

Teknik analisis data yang digunakan yakni menggunakan SPSS for windows ver. 21 menggunakan uji paired sample t-test. Pengujian ini dilakukan untuk mengetahui pengaruh intervensi yang diberikan pada subjek.

\section{Hasil dan pembahasan}

Data penelitian yang sudah diperoleh kemudian dianalisis menggunakan paired sample t-test. Berikut adalah hasil pengujian data sebelum dan sesudah diberikan intervensi: Tabel 1: Hasil Pengujian Skala Stres Akademik

\begin{tabular}{lcccccc}
\hline Kelompok & N & \multicolumn{2}{c}{$\begin{array}{c}\text { Rerata } \\
\text { Nilai }\end{array}$} & t hit & $\begin{array}{c}\text { t } \\
\text { tab }\end{array}$ & $\begin{array}{c}\text { Sig. } \\
(\boldsymbol{p})\end{array}$ \\
\cline { 3 - 4 } & & $\begin{array}{c}\text { Pre- } \\
\text { test }\end{array}$ & $\begin{array}{c}\text { Post- } \\
\text { test }\end{array}$ & & & \\
\hline $\begin{array}{l}\text { Kelompok } \\
\text { intervensi }\end{array}$ & 5 & 84.2 & 59.8 & & 2.26 & \\
\hline
\end{tabular}

Berdasarkan tabel output diatas, diketahui bahwa tedapat penurunan nilai rata-rata skor pre-test dengan skor post-test. Dimana nilai rata-rata skor pre-test sebesar 84.2 dan ratarata skor post-test 59.8. Hal ini berarti setelah diadakannya intervensi terjadi penurunan skor rata-rata sebesar 24.4. Jika dilihat dari angka probabilitas $(\mathrm{p}=0.01<0.05)$, artinya skor tersebut signifikan. Hal ini menunjukan bahwa antara skor sebelum dan skor sesudah intervensi menunjukan adanya penurunan stres akademik secara signifikan.

Jika dilihat dari perolehan skor skala stress akademik antara sebelum dan sesudah intervensi, diperoleh hasil jika masing-masing subjek mengalami penurunan tingkat stress akademik. Berikut grafik penurunan tingkat stress akademik masing-masing subjek:

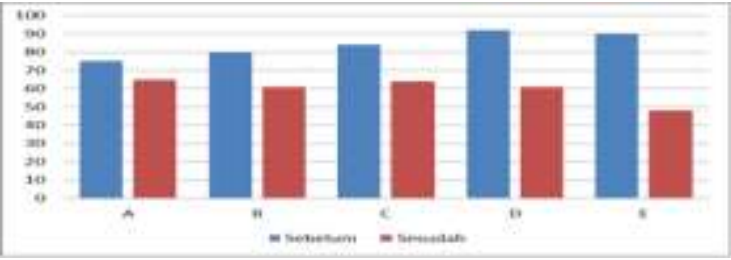

Grafik 1: Tingkat Stress Akademik Sebelum dan Sesudah Intervensi

Berdasarkan Grafik 1, diketahui bahwa subyek A, subyek B,subyek C, subyek D dan subyek $\mathrm{E}$ mengalami perubahan skor antara sebelum dilakukan intervensi dengan sesudah dilakukan intervensi. Artinya keseluruhan subjek mengalami penurunan skor stress akademik setelah intervensi.

Stress umumnya ditandai dengan adanya gejala fisik dan psikis. Gejala fisik seperti sakit kepala, sakit lambung, hipertensi, jantung berdebar, insomnia, mudah lelah, keringat dingin, tidak ada nafsu makan dan sering buang air kecil. Sedangkan gejala psikis ditandai dengan gelisah, kurang bisa konsentrasi, apatis, sering melamun, mudah marah dan bersikap agresif. Biasanya kedua gejala ini, yaitu fisik dan psikis berjalan beriringan (Khairanis 2006).

Intervensi dilakukan dengan menggunakan dua teknik, yaitu focus group discussion (FGD) dan psikodrama. Sebelum dan sesudah dilakukan intervensi, masingmasing subyek diberikan skala pre-test dan post test untuk mengukur tingkat stres akademik. Setelah semua kegiatan intervensi sudah dilakukan, masing-masing subyek diberikan skala post-test untuk melihat perubahan tingkat stres mereka sesudah mendapatkan intervensi. Perolehan skor post test juga didukung dari self monitoring subyek pada saat dilakukan sesi terakhir. Dimana subyek sudah bisa merubah persepsi mereka terhadap masalah yang mereka hadapi. Hal ini menunjukan bahwa teknik intervensi yang dilakukan mempunyai pengaruh terhadap permasalahan yang dihadapi oleh masingmasing subyek. Focus group discussion (FGD) dilakukan dengan memberikan sebuah kasus, subyek dituntut mampu mendiskusikan 
permasalahan tersebut. Kasus tersebut akan menjadi stimulus untuk subyek sehingga mereka bisa merubah pemikiran mereka (Boateng, 2012). Begitu pula dengan psikodrama, dimana dalam psikodrama ini subyek memainkan peran dan dari situ mereka bisa menemukan solusi dari permasalahannya. Dari sini subjek tidak bisa sharing permasalahan dengan subjek lain sehingga tidak merasa mempunyai permasalahan sendiri (Wilks, 2008).

Selama pelaksanaan psikodrama menggunakan tempat yang menyerupai panggung agar para subjek leluasa bermain peran. Permainan peran dalam psikodrama digunakan untuk memerankan dirinya sendiri maupun oranglain dikehidupan nyata (Orkibi, 2018). Disini subjek akan merasa bebas mengekpresikan sikap dan gerak secara spontan (Lubis, 2016). Saat psikodrama para subjek berpartisipasi aktif, spontanitas dan kreatif dalam mengatasi masalah, baik permanen atau tarnsisional. Peran antagonis bisa mendapatkan feedback dari penonton dan peran pembantu dan sebaliknya. Dalam hal ini baik peran antagonis, penonton dan peram pembantu dapat meluapkan emosi (Lubis, 2016).

Focus group discussion dan psikodrama dapat membantu subjek untuk mengembangkan kemampuan coping yang mereka dapatkan dari beberapa sudut pandang. Kemampuan coping inilah yang kemudian dapat diterapkan dalam kehidupan nyata ketika menghadapi stressor. Para subjek akan terhindar dari stress akademik jika mereka mampu mengatasinya dengan benar dan tidak menghindar.

\section{Simpulan}

Kegiatan intervensi yang telah dilakukan menunjukan adanya penurunan skor stres akademik pada subyek secara signifikan. Perubahan tingkat stress akademik subjek terlihat dari perolehan skor skala stress akademik pada masing-masing subjek. Skor rata-rata telah terjadi penurunan antara sebelum intervensi dan sesudah intervensi.
Artinya kegiatan intervensi ini menunjukan hasil sesuai dengan target penelitian karena tiap subjek mengikuti kegiatan dari sesi pertama sampai akhir. Pada sesi terakhir subyek belajar mengembangkan strategi coping dari berbagai sudut pandang antar subyek.

\section{Daftar Rujukan}

Agolla, J. E. \& Ongori, H. (2009). An Assessment of Academic Stress among Undergraduate Students: The Case of University of Botswana. Educational Research and Review, 4(2), 63-70.

Ang, R. P. \& Huan, V. S. (2006). Relationship between Academic Stress and Suicidal Ideation: Testing for Depression as a Mediator using Multiple Regression. Child Psychiatry and Human Development, 37(2), 133-143.

Boateng, W. (2012). Evaluating the Efficacy of Focus Group Discussion (FGD) in Qualitative Social Research. International Journal of Business and Social Science, 3(7), 54-57.

Blatner, A. (2000). Foundation of Psychodrama, Fourth Editiion. New York: Springer Publishing Company.

Jogaratnam, G. \& Buchanan, P. (2004). Balancing the Demands of School and Work: Stress and Employed Hospitality Students. International Journal of Contemporary Hospitality Management, 16(4), 237-245.

Khairanis. (2006). Stress dan perilaku coping para terapis dalam menghadapi anak autism. Skripsi S1. Fakultas Psikologi Universitas Islam Negeri. Jakarta.

Klonsky, J. \& Hoe, R. (2003). Sources and Levels of Stress among UCLA Students. Student Affairs Briefing, 2.

Kumar, S. \& Jejurkar, K. (2005). Study of Stress Level in Occupational Therapy Students during their Academic Curriculum. The Indian Journal of Occupational Therapy, 37 (1), 5-14.

Lubis, N.L. (2016). Konseling kelompok. Jakarta: Kencana. 
Misra, R. \& McKean, M. (2000). College Students'Academic Stress and its Relation to Their Anxiety, Time Management, and Leisure Satisfaction, Am. J. Health Stud, 16(1): 41-51.

Orkibi, H. (2018). The User-Friendliness of Drama: Implications for Drama Therapy and Psychodrama Admission and Training. Israel: University of Haifa.

Santrock, J. W. (2012). Life-span Development. 13 th Edition. University of Texas, Dallas : Mc Graw-Hill.
Seniati, L., Yulianto, A., \& Setiadi, B. N. (2011). Psikologi eksperimen. PT. Indeks.

Sutardjo, A. W. (2005). Pengantar Psikologi Abnormal. Bandung: PT Refika Aditama..

Wilks, S. E. (2008). Resilience amid Academic Stress: The Moderating Impact of Social Support among Social Work Students. Advances in Social Work, 9(2), 106-125. 